\title{
Comparative Anatomical Study of Lungs in Domestic Rabbits (Oryctolagus cuniculus) and Guinea Pigs (Cavia porcellus)
}

\author{
Florin STAN \\ Department of Comparative Anatomy, Faculty of Veterinary Medicine Cluj - Napoca, University of \\ Agricultural Sciences and Veterinary Medicine, Cluj - Napoca, 3-5, Mănăștur Street, 400372, Romania. \\ Corresponding author: flodvm@yahoo.com
}

Bulletin UASVM Veterinary Medicine 72(1) / 2015,

Print ISSN 1843-5270; Electronic ISSN 1843-5378

DOI:10.15835/buasvmcn-vm: 10588

\begin{abstract}
Rabbits and guinea pigs are small mammals with high metabolic rate and higher oxygen demands compare to large animals. Increased oxygen intake is favored not by larger lungs but by a serials of anatomical modification of conformation, airwaves distribution and structure. Using gross dissection the lung anatomy and division was documented. Both rabbits and guinea pigs are nose breathers because larynx is placed high in the oropharynx where it can directly access the nasopharynx. The lungs were asymmetrical in dimensions; the right lung being larger than the left lung, having the same lobe divisions: cranial, middle and caudal. In rabbits the thorax is small in contrast with the large abdomen. The thymus is frequently found in adult rabbits. In guinea pigs the lungs show deep incisures. Both in rabbits and guinea pigs respiration is made due to the anatomical particularities of thoracic cavity and its components with diaphragm acting as the main respiratory muscle.
\end{abstract}

Keywords: anatomy, guinea pig, lungs, rabbit, thoracic cavity

\section{INTRODUCTION}

Comparative studies of respiratory system in common laboratory animals are useful to reveal unique species variations which could be useful in selection of animal models for directed studies. Rabbits, guinea pigs and Greyhound dogs are valuable models in respiratory research due to their respiratory hyperresponsiveness that resemble asthma in humans (Martin 1994). To asses lung function impairment is required a good knowledge of respiratory system, especially of the main organs involved in breathing -the lungs.

\section{AIMS AND OBJECTIVES}

The aim of the present research is to achieve a detailed and comparative morphological description of lungs in rabbits and guinea pigs.

\section{MATERIALS AND METHODS}

Ten adult rabbits and ten guinea pigs were used. Using appropriate anatomical technique the thoracic cavity was opened and the organs were photographed in situ. After removal from the thoracic cavity the lobes of the lungs were individualized and photographed.

\section{RESULTS AND DISCUSSIONS}

In rabbits, the thoracic cavity was smallest compared to their large abdominal cavity, while in guinea pigs the thoracic cavity was slightly larger. The heart in guinea pigs occupies a large part of the thoracic cavity leaving a narrow space for the lungs on each side.

The left lung (Pulmo sinister) in rabbit and guinea pigs shows three lobes: cranial (Lobus cranialis), middle (Lobus medius) and caudal lobe (Lobus caudalis). The right lung (Pulmo dexter) present four lobes: cranial, middle, caudal and accessory (Lobus accessorius). As in dogs, but unlike in rats and mice, in rabbits, the left lung is smaller compare to the right lung. The left cranial lung lobe was smaller due to the heart interposition and its left deviation. The middle left lobe was very small and present esophagus imprint (Impressio 

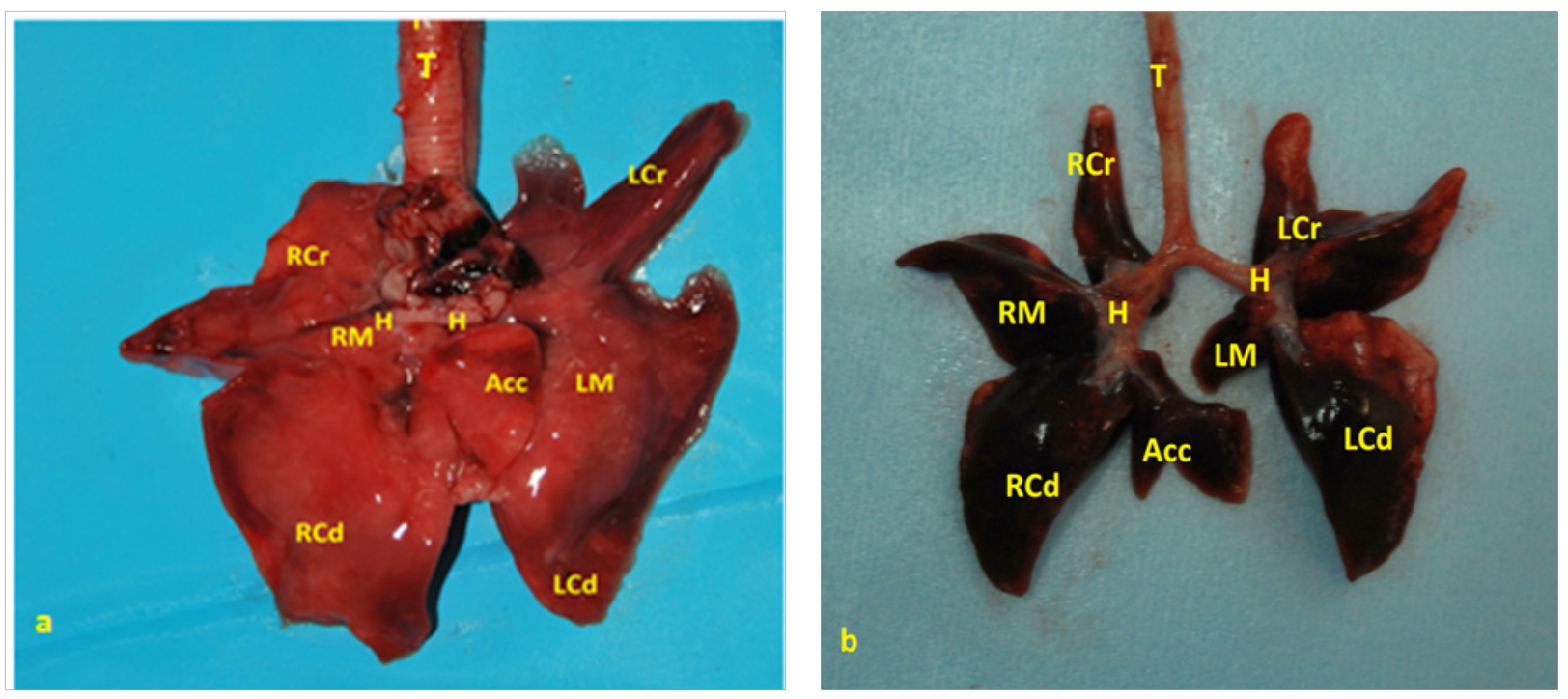

Fig. 1. The lungs lobes in rabbit (left-1a) and guinea pigs (right-1b). T-trachea; RCr-right cranial lung lobe; RM-right medial lung lobe; RCd-right caudal lung lobe; Acc-accessory lobe; H-hillus. Note the presence of a intralobar fissure that divide the left cranial lobe in guinea pigs and the presence of deep incisures of lungs.

esophagea) (Stan, 2013). The right caudal lobe was the larger lobe (Fig.1a). In guinea pigs, the left cranial lobe show a deep intralobar fissure that divides it into a smaller cranial segment and a larger caudal segment. The small medial lobe presents the esophagus imprint. The left caudal lobe was the larger lobe (Fig.1b). The right cranial lobe was small and the right medial lobe has a concave cardiac impression (Impressio cardaica). As in rabbits, the right caudal lobe was the larger lobe. In rabbits, cranioventrally to the heart extending forward to the thoracic inlet, we noticed the presence of thymus, composed of three lobes, in six subjects. The main left thymus lobe was larger than the right dorsal and ventral lobes. This feature was not found in guinea pigs, but in the ventral cervical area and in cranial mediastinum it was noticed the presence of a small amount of adipose tissue. Both in rabbis and guinea pigs the lungs lacks of septa, which in majority of animals split the lobes into lobules (Barone, 1997), therefore an anatomical explanation of absence of lobular pneumonia in these species is provided.

\section{CONCLUSIONS}

The principal respiratory organs in rabbits and guinea pigs, the lungs, are morphologically adapted to the increased need of oxygen in these species and to their small thoracic cavity size.

The rabbits and guinea pigs share the same division of lungs: three left lung lobes and four right lung lobes.

In guinea pigs, the lungs have deep incisures compare to the rabbits.

In adult rabbits, the presence of thymus in the cranial mediastinum is not unusual.

\section{REFERENCES}

1. Barone R (1997). Anatomie comparée des mammifères domestiques. Vol 3, 3ed, Vigot Fréres, Paris, 783.

2. Martin JG (1994). Animal models of bronchial hyperresponsiveness. Rev Mal Respir 11(2):93-99.

3. Nomina Anatomica Veterinaria (fifth edition) 2012.

4. Stan F (2013). Comparative Study of the Stomach Morphology in Rabbit and Chinchilla. AgroLifeScientific Journal, Bucuresti, Romania (2):73-78. 